\title{
Lung Lymphocyte Elimination by Apoptosis in the Murine Response to Intratracheal Particulate Antigen
}

\author{
Alicja M. Milik, ${ }^{\star}$ Virginia A. Buechner-Maxwell, ${ }^{\star}$ Joanne Sonstein, ${ }^{\star}$ Sucha Kim, ${ }^{\star}$ Gerami D. Seitzman, ${ }^{\star}$ Ted F. Beals, ${ }^{\ddagger}$ \\ and Jeffrey L. Curtis ${ }^{\star}$ \\ Pulmonary \& Critical Care Medicine Division, *Department of Internal Medicine, and the ${ }^{\ddagger}$ Department of Pathology, \\ University of Michigan, Ann Arbor, Michigan 48109-0760; and ${ }^{\S}$ Pulmonary Section and the "Laboratory Medicine Section, \\ Department of Veterans Affairs Medical Center, Ann Arbor, Michigan 48105-2303
}

\begin{abstract}
Pulmonary immune responses are suited to determine mechanisms of lymphocyte elimination, as lung inflammation must be regulated tightly to preserve gas exchange. The selfterminating response of primed C57BL/6 mice to intratracheal challenge with the T cell-dependent Ag sheep erythrocytes (SRBC) was used to test the importance of lung lymphocyte apoptosis in pulmonary immunoregulation. Apoptosis of alveolar and interstitial lymphocytes was demonstrated morphologically, by three independent methods to detect DNA fragmentation, and by surface expression of phosphatidylserine. Apoptotic lymphocytes were exclusively $\mathrm{CD}^{-}, \mathrm{CD}^{-}, \mathrm{B}^{2} 20^{-}$, but many were $\mathrm{CD}^{+}$and Thy $1^{+}$. Inhibiting apoptosis by in vivo cyclosporine treatment prolonged lung lymphocyte accumulation following SRBC challenge. Experiments using mice homozygous for the lpr or gld mutations showed that pulmonary lymphocyte apoptosis depended on expression of Fas (CD95) and its ligand (Fas-L). Pulmonary inflammation increased on repeated intratracheal SRBC challenge of lpr/lpr mice, in contrast to the waning response in normal mice. These results confirm that in situ lymphocyte apoptosis contributes to termination of immune responses in nonlymphoid organs, probably because of activation-induced cell death, and may be important in inducing tolerance to repeated antigen exposure. $(J$. Clin. Invest. 1997. 99:1082-1091.) Key words: cell survival • cyclosporins $\bullet$ disease models, animal $\bullet$ immune tolerance • T lymphocytes
\end{abstract}

Portions of these data were presented to the Southern Society for Clinical Investigation (New Orleans, LA; 5 February 1994), at the Keystone Conference on Cellular \& Molecular Immunology (Keystone, CO; 14 April 1994), at the International Scientific conference of the American Thoracic Society (Boston, MA; 22 May 1994), and have been published in abstract form (Clin. Res. 1993; 41:774A, 1993, and J. Cell Biochem. 1994; Supplement 18D:414).

Address correspondence to Jeffrey L. Curtis, M.D., Pulmonary Section (111G), Department of Veterans Affairs Medical Center, 2215 Fuller Road, Ann Arbor, MI 48105-2303. Phone: 313-761-7980; FAX: 313-761-7843; E-mail: jlcurtis@umich.edu

Received for publication 27 October 1995 and accepted in revised form 12 December 1996.

The Journal of Clinical Investigation

Volume 99, Number 5, March 1997, 1082-1091

\section{Introduction}

Pulmonary immune responses must be regulated tightly to protect the lungs against pathogens without interfering with gas exchange. The challenge of this regulation is daunting, given the enormous area of alveolar epithelium, the constant threat of aspirated or inhaled antigens, and the presence within pulmonary vasculature of many activated lymphocytes $(1,2)$. Several mechanisms limit development of pulmonary immune responses. Alveolar macrophages, the predominant resident phagocyte, are relatively poor antigen-presenting cells $(3,4)$ that secrete factors inhibiting lymphocyte proliferation $(5,6)$. Although alveolar macrophages can transport particles to mediastinal nodes to initiate immune responses (7), eliminating alveolar macrophages increases pulmonary immune responses (8), suggesting that their net effect is inhibitory. Alveolar lining fluid also inhibits lymphocyte proliferation in vitro, because of both lipid and protein components $(9,10)$. Thus, control of lung lymphocyte activation and proliferation potentially control the magnitude and duration of pulmonary immune responses.

Another potential regulatory mechanism is elimination of immunocompetent cells via apoptosis. Apoptosis is a type of energy-dependent cell death associated with endonuclease activation (11). Apoptosis is recognized morphologically on transmission electron microscopy (TEM) ${ }^{1}$ by condensation of nuclear chromatin with retained integrity of cellular membranes and mitochondria. The biochemical hallmark of apoptosis is chromatin fragmentation into oligonucleosomes. In vitro, apoptosis is induced in mature $\mathrm{T}$ lymphocytes following CD3 cross-linking in a process known as activation-induced cell death (AICD) $(12,13)$; however, there is little direct evidence of AICD of mature peripheral lymphocytes during immune responses in vivo (14). Lymphocyte apoptosis also occurs in vitro and in vivo in responses to superantigens (15) and following cross-linking of CD4 by antibody or by gp120 of HIV $(16,17)$. While these processes may be identical to AICD, apoptosis might be induced in these settings by unphysiologic signal transduction. The importance of apoptosis for lymphocyte clearance from sites of inflammation and the mechanisms by which it is induced in vivo remain undefined. There is no

1. Abbreviations used in this paper: AICD, activation-induced cell death; BAL, bronchoalveolar lavage; $\mathrm{CD}^{+} \mathrm{DN}, \mathrm{CD}^{+}$double negative; PI, propidium iodine; SRBC, sheep red blood cells; TEM, transmission electron microscopy; TUNEL, terminal deoxynucleotidyl transferase-mediated dUTP-biotin nick end labeling. 
evidence that lymphocyte apoptosis contributes to the regulation of pulmonary immune responses.

The relative importance of immunoregulatory mechanisms can not be predicted accurately based solely on in vitro observations, but must be assessed within intact organisms. To this purpose, we and others have analyzed the response to intratracheal challenge with the particulate, $\mathrm{T}$ cell-dependent Ag sheep red blood cells (SRBC) (18). This secondary pulmonary immune response is characterized by peribronchovascular mononuclear cell accumulation, transient pulmonary angiitis, and in situ maturation of specific antibody-secreting cells (1921). The response is self-limiting over 14-21 d. The goal of this study was to use this model system to determine whether apoptosis contributes to pulmonary immune response termination by eliminating lung lymphocytes.

\section{Methods}

Animals. Specific pathogen-free female C57BL/6J mice were obtained at 7-8 wk of age and C57BL/6J $l p r / l p r$, MRL lpr/lpr, MRL +/+, $\mathrm{C} 3 \mathrm{H} / \mathrm{HeJ}$ gld/gld, and $\mathrm{C} 3 \mathrm{H} / \mathrm{HeJ}+/+$ mice were obtained at 5-6 wk of age from Jackson Laboratories (Bar Harbor, ME). Mice were housed in the Animal Care Facility at the Ann Arbor VA Medical Center, which is fully accredited by the American Association for Accreditation of Laboratory Animal Care. This study complied with the NIH "Guide for the Care and Use of Laboratory Animals" (DHEW Publication No. [NIH] 80-23). Mice were fed standard animal chow (Rodent Lab chow 5001, Purina; St. Louis, MO) and chlorinated tap water ad libitum. C57BL/6J mice were used at 8-14 wk of age; lpr and gld mice and their age-matched control mice were used before $12 \mathrm{wk}$ of age.

$m A b s$. The following $\mathrm{mAbs}$ were purchased from PharMingen (San Diego, CA): RM2-5 (anti-CD2); 145-2C-11 (anti-CD3- $\epsilon$ ); RM4-4 (anti-CD4); 53-6.72 (anti-CD8); 17/4 (anti-CD11a); 7D4 (anti-CD25); IM7.8 (anti-CD44); 30F11.1 (anti-CD45); RA3-6B2 (anti-CD45/B220 isoform); R1-2 (anti-CD49d); MEL-14 (anti-CD62L/L-selectin); H1.2 F3 (anti-CD69); 30H12 (anti-CD90/Thy 1.2). mAbs were either directly FITC-conjugated or biotinylated; in the latter case staining was visualized using streptavidin-PE (PharMingen). Isotype matched irrelevant control antibodies were tested simultaneously to exclude nonspecific staining. Immunofluorescence staining and analysis on a FACSCAN $^{\circledR}$ flow cytometer (Becton Dickinson, Mountain View, CA) was performed as previously described (22).

Induction of pulmonary immune response to SRBC. SRBC (sheep 4151) (Colorado Serum Co., Denver, CO) were washed three times in $7 \mathrm{ml}$ normal saline before use. Mice were primed by intraperitoneal injection with $1 \times 10^{8} \mathrm{SRBC}$ in $0.5 \mathrm{ml}$ normal saline. 2 wk later, mice were intratracheally challenged with $5 \times 10^{8} \mathrm{SRBC}$ in $50 \mu \mathrm{l}$ normal saline (23). Our technique causes the majority of $\mathrm{Ag}$ to be deposited and retained in alveoli (24) and results in a highly reproducible pulmonary immune response (19-21).

In vivo inhibition of lymphocyte apoptosis. In some experiments, mice were injected by the IP route with cyclosporine A (CsA) (Sandimmune $^{\circledR}$; Sandoz, East Hanover, NJ), $25 \mathrm{mg} \cdot \mathrm{kg}^{-1} \cdot \mathrm{d}^{-1}$ (dissolved in ethanol) (25). Treatment was begun $1 \mathrm{~d}$ before intratracheal $\mathrm{Ag}$ challenge and was continued daily until the mice were killed.

Killing of mice and collection of tissues. At various times from 2-9 d after intratracheal $\mathrm{Ag}$ challenge, mice were deeply anesthetized with pentobarbital $\left(80 \mathrm{mg} \cdot \mathrm{kg}^{-1}\right.$ i.p.) and killed by exsanguination. Bronchoalveolar lavage (BAL) and differential cell counts were performed as previously described (20).

In some experiments, lymph nodes and thymuses were obtained by dissection from young normal mice. Lungs, thymuses, and lymph nodes to be processed for DNA electrophoresis were snap frozen immediately by immersion in liquid nitrogen and were stored wrapped in Parafilm and aluminum foil at $-70^{\circ} \mathrm{C}$ for use within 1 mo. Thymuses were mashed using a 60 gauge stainless steel mesh, washed twice in PBS and suspended at 5-10 × $10^{6}$ cells $/ \mathrm{ml}$ in RPMI 1640 medium containing $10 \%$ FBS, penicillin, streptomycin, gentamicin, and $5 \times 10^{-5} \mathrm{M}$ 2-ME (all from Gibco Laboratories, Grand Island, NY) (complete medium).

Induction of apoptosis in control thymocytes. Thymocytes were cultured overnight $(20-24 \mathrm{~h})$ at $37^{\circ} \mathrm{C}$ in a $5 \% \mathrm{CO}_{2}$ environment in complete medium supplemented with $1 \times 10^{-7} \mathrm{M}$ dexamethasone (Sigma Chemical Co., St Louis, MO) (26). Negative control thymocytes were cultured overnight in complete medium without dexamethasone at $4^{\circ} \mathrm{C}$.

Analysis of lymphocyte DNA fragmentation in isolated nuclei by gel electrophoresis. BAL cells were depleted of mononuclear phagocytes which could contain ingested apoptotic cells using Sephadex G-10 column chromatography (27). 3-5 million BAL cells were pelleted and gently resuspended in $500 \mu \mathrm{l}$ Nuclei buffer $(10 \mathrm{mM}$ Hepes, 0.3 $\mathrm{mM}$ sucrose, $10 \mathrm{mM} \mathrm{KCl}, 0.1 \mathrm{mM}$ EDTA, $1.5 \mathrm{mM} \mathrm{MgCl}_{2}$, and $0.5 \mathrm{mM}$ DTT), incubated on ice for $10 \mathrm{~min}$, centrifuged at $350 \mathrm{~g}$ at $4^{\circ} \mathrm{C}$ for 5 min. The pellet was resuspended in $200 \mu \mathrm{l}$ cold Nuclei buffer, $200 \mu \mathrm{l}$ TE buffer, $16 \mu \mathrm{l} 0.5 \mathrm{M}$ EDTA, $20 \mu \mathrm{l} 10 \%$ SDS; the mixture was digested with proteinase $\mathrm{K}$ in a shaking water bath at $37^{\circ} \mathrm{C}$ for $2-4 \mathrm{~h}$. Next, DNA was extracted twice, first with phenol and second with chloroform/isoamyl alcohol (24:1). The aqueous phase was precipitated overnight using $2 \mathrm{vol}$ of ethanol at $-20^{\circ} \mathrm{C}$. The precipitated pellets were air-dried and resuspended in $50 \mu \mathrm{l}$ TE buffer. DNA concentration was calculated by determining the $\mathrm{OD}$ at $260 \mathrm{~nm}$. Horizontal electrophoresis of DNA (10 $\mu \mathrm{g}$ per well) was performed for $2 \mathrm{~h}$ at $100 \mathrm{~V}$ using a $1.8 \%$ agarose gel containing $0.6 \mu \mathrm{g}$ ethidium bromide per $125 \mathrm{ml} 1 \times$ TAE buffer. DNA was visualized by ultraviolet transillumination and immediately photographed using a DS34 direct screen instant camera (Polaroid, Cambridge, MA).

Analysis of DNA fragmentation in tissue sections. Formalin-fixed, paraffin-embedded sections of lung tissue were stained by the terminal deoxynucleotidyl transferase (TdT)-mediated dUTP nick end labeling (TUNEL) technique (28) using an FITC-conjugated APOTAG kit (Oncor Inc., Gaithersburg, MD), according to the manufacturer's recommendations.

Analysis of DNA fragmentation by flow cytometry. DNA fragmentation in individual lymphocytes was demonstrated by detecting hypodiploid DNA content by propidium iodine (PI) staining, using the method of Noguchi (29). In some experiments, surface markers were also stained as follows: $1 \times 10^{6} \mathrm{BAL}$ cells were suspended in $100 \mu \mathrm{l}$ PBS containing $0.9 \mathrm{mM} \mathrm{Ca}^{2+}, 0.5 \mathrm{mM} \mathrm{Mg}^{2+}$, and $0.001 \%$ sodium azide $\left(\mathrm{PBS}^{2+} \mathrm{A}\right)$. Cells were incubated in $12 \times 75 \mathrm{~mm}$ polypropylene tubes with saturating concentrations of $\mathrm{mAbs}$ in the dark at $4^{\circ} \mathrm{C}$ for $20 \mathrm{~min}$, and then were washed twice in cold $\mathrm{PBS}^{2+} \mathrm{A}$. Cells were fixed for $1 \mathrm{~h}$ in cold $70 \%$ ethanol, followed by washing twice with PBS (without cations or azide). Cells were then incubated in $100 \mu \mathrm{l}$ RNase Type 1-A (Sigma Chemical Co.) at $1 \mathrm{mg} / \mathrm{ml}$ in PBS at room temperature for $15 \mathrm{~min}$. Next, $200 \mu \mathrm{l}$ of PI at $100 \mathrm{mg} / \mathrm{ml}$ in PBS were added to the solution and the mixture was incubated overnight in the dark at $4^{\circ} \mathrm{C}$. Apoptosis was also demonstrated in some experiments by demonstrating cell surface expression of phosphatidylserine (30) using fluoresceinated annexin V (PharMingen) and flow cytometry (31).

Statistical analysis. Data were expressed as mean \pm SEM. Continuous ratio scale data were evaluated by paired Student's $t$ test (32). Statistical calculations were performed on a Macintosh PowerPC 8100/88AV computer using the programs Statview 4.0 and SuperANOVA (Abacus Concepts, Berkeley, CA). Statistical difference was accepted at $P<0.05$.

\section{Results}

Lung lymphocytes undergo apoptosis during the pulmonary immune response. Lung lymphocyte apoptosis was demonstrated by a variety of morphologic and biochemical tech- 

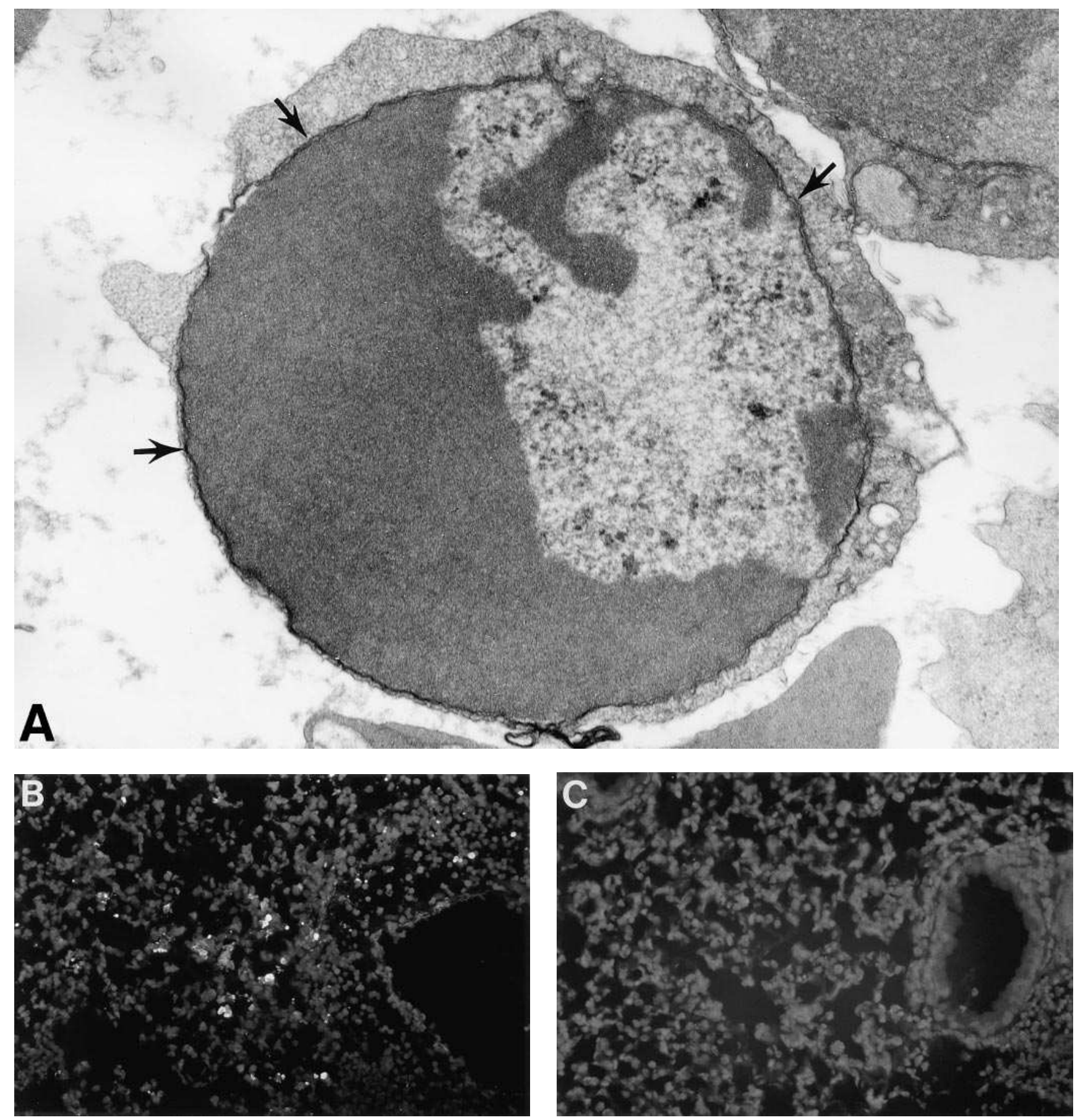

Figure 1. Morphologic evidence of lung lymphocyte apoptosis. A secondary pulmonary immune response was induced by intratracheal challenging primed C57BL/6J mice using SRBC. On various days after challenge, alveolar cells were obtained by BAL; lungs and an aliquot of BAL were fixed in $2 \%$ glutaraldehyde, post-fixed in osmium tetroxide and processed for TEM. The remainder of the lungs were paraffin-embedded, sectioned, and processed to detect DNA fragmentation by TUNEL (28). (A) TEM of BAL lymphocyte ( $3 \mathrm{~d}$ after Ag challenge) showing early nuclear condensation (arrows indicate nuclear membrane); $\times 15,600$. $(B-C)$ Apoptotic lymphocytes in lung section $(7 \mathrm{~d}$ after Ag challenge). $(B)$ FITC-positive apoptotic cells in perivascular cellular infiltrates; $(C)$ negative control (TdT omitted); both $\times 400$. Representative of five experiments.

niques. TEM showed that typical nuclear chromatin condensation was frequent among unseparated BAL lymphocytes (Fig. $1 A$ ). Essentially, all cells which showed typical nuclear chromatin condensation were small to medium sized lymphocytes. Apoptotic mononuclear cells were also identified in lung sections by TEM and by the TUNEL technique (28) (Fig. 1, $B$ and $C$ ), indicating that apoptosis was neither an artifact of the BAL procedure nor limited to alveolar cells.

DNA from BAL lymphocytes (Sephadex G-10 passed) demonstrated characteristic internucleosomal cleavage (Fig. 2). DNA fragmentation was easily detectable $2 \mathrm{~d}$ after challenge, and persisted to day 9. However, DNA fragmentation 


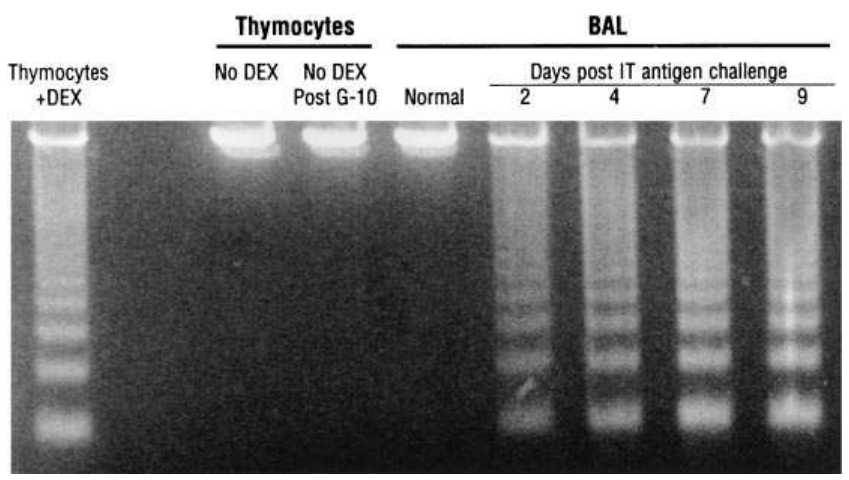

Figure 2. Electrophoretic analysis of DNA from BAL lymphocytes. Thymocytes from normal mice were cultured overnight either at $37^{\circ} \mathrm{C}$ with $10^{-7} \mathrm{M}$ dexamethasone ( $+\mathrm{DEX}$ ) or at $4^{\circ} \mathrm{C}$ in medium alone (no $\mathrm{DEX})$ as positive and negative controls, respectively. BAL lymphocytes obtained from normal C57BL/6J mice or SRBC-primed C57BL/ $6 \mathrm{~J}$ mice on the indicated day after intratracheal (IT) Ag challenge were depleted of mononuclear cells and granulocytes using G-10 columns. DNA was obtained as described (60) from isolated nuclei and fragmentation was demonstrated by electrophoresis. Note DNA fragmentation in BAL samples from 2-9 d after antigen challenge. Representative of three experiments.

was not detected in BAL from normal mice by this technique (Fig. 2, lane 5). Control experiments showed that this technique was insensitive to the presence of fewer than 18-20\% apoptotic cells (not shown). Further control experiments indicated that identical treatment over G-10 columns did not induce apoptosis (as determined by DNA fragmentation on ethidium bromide-agarose gel electrophoresis) in thymocytes (Fig. 2, lane 4), EL-4 lymphoma cells or normal lymph node lymphocytes (not shown). Differential cell counts showed that following elution from G-10 columns, BAL cells were 90-97\% small lymphocytes and 2-3\% macrophages.

Quantification of lung lymphocyte apoptosis. Apoptotic BAL lymphocytes were quantified by two independent flow cytometric assays: PI staining (29), which demonstrates characteristic hypodiploid DNA content, and annexin staining which demonstrates surface expression of phosphatidylserine (30, 31). These assays do not require separation of BAL cells because lymphocytes can be identified by light scatter gating. BAL of normal mice contained $16.3 \pm 4.3 \%$ apoptotic lymphocytes (seven experiments) by PI assay, and $18.3 \pm 7.7 \%$ apoptotic lymphocytes (four experiments) by annexin staining. Analysis of antigen-primed mice $3 \mathrm{~d}$ after sham intratracheal challenge using saline yielded $4.3 \pm 0.3 \times 10^{5}$ total BAL cells per mouse and $23.4 \pm 3.6 \%$ apoptotic lymphocytes by annexin assay ( $n=15$ mice assayed in pooled groups of five mice). After antigen challenge the percentage of apoptotic lymphocytes increased sharply and remained elevated to day 6 before declining somewhat (Fig. 3). The two assays gave comparable results (it should be noted that they were performed in independent experiments); in further studies we used PI staining to quantify lymphocyte apoptosis.

Two-color flow cytometry showed that apoptosis was confined to cells devoid of CD4, CD8, and B220 (Fig. 4 A). Absence of staining for these receptors was a consistent finding seen in each of three experiments. However, most apoptotic cells were $\mathrm{CD}^{+}$(Fig. 4 B) and Thy $1^{+}$(not shown), confirming
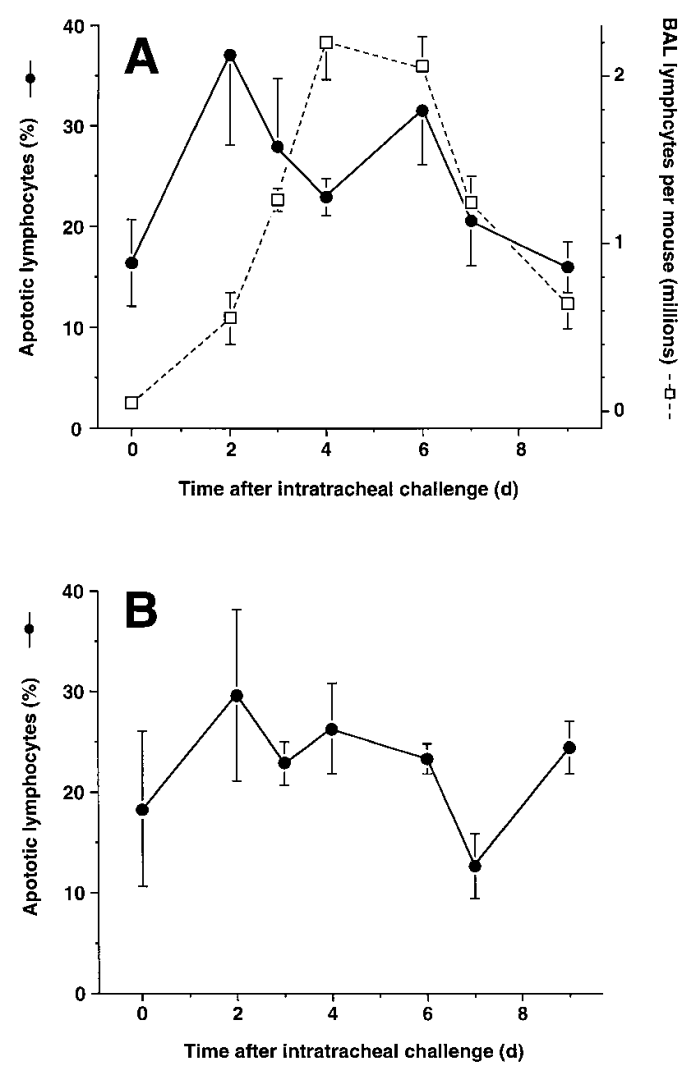

Figure 3. Quantification of lung lymphocyte apoptosis by flow cytometry. Apoptotic BAL lymphocytes obtained from normal or SRBC-primed C57BL/6J mice were detected by hypodiploid DNA content visualized by PI staining (29) $(A)$ or in independent experiments by presence of cell surface phosphatidylserine $(30,31)(B)$. Samples were analyzed by flow cytometry with scatter gating to identify lymphocytes. ( $A$ ) Right axis and circles $(-)$ denote percentage of apoptotic lymphocytes, left axis and squares $(\square)$ denote total BAL lymphocytes per mouse; time zero represents normal mice (primed mice not receiving intratracheal challenge gave identical results). Data are mean \pm SEM of samples from 2-6 individual mice in each of five experiments per time-point (PI staining) or four experiments (annexin staining), except for the normal mice, in which groups of 2-3 mice were pooled in each of four experiments.

that they were $\mathrm{T}$ cells. Thus, these cells appear to be $\mathrm{CD} 3^{+}$ double negative $\left(\mathrm{CD}^{+} \mathrm{DN}\right)$ cells $(33)$. Apoptotic cells were also negative for the following surface markers: CD2, CD11a, CD25, CD44, CD45, CD62L (L-selectin). Interestingly, there was a substantial population of lung lymphocytes which were negative for CD4, CD8, and B220, yet without detectable DNA fragmentation. Sham intratracheal challenge also yielded $21.4 \pm 3.7 \%$ lymphoid cells negative for CD4, CD8, and B220.

Blockade of lung lymphocyte apoptosis prolongs lung inflammation. To evaluate the significance of lung lymphocyte apoptosis for pulmonary immune response termination, we treated mice with the immunosuppressive agent CsA. CsA blocks calcineurin, preferentially inhibiting responses dependent on increased intracellular calcium, including apoptosis both in vivo and in vitro $(25,34)$. To ensure adequate systemic levels, CsA was administered $1 \mathrm{~d}$ and again $1 \mathrm{~h}$ before intratracheal Ag challenge (25). CsA treatment blocked lung lymphocyte apoptosis as determined by gel electrophoresis (not 

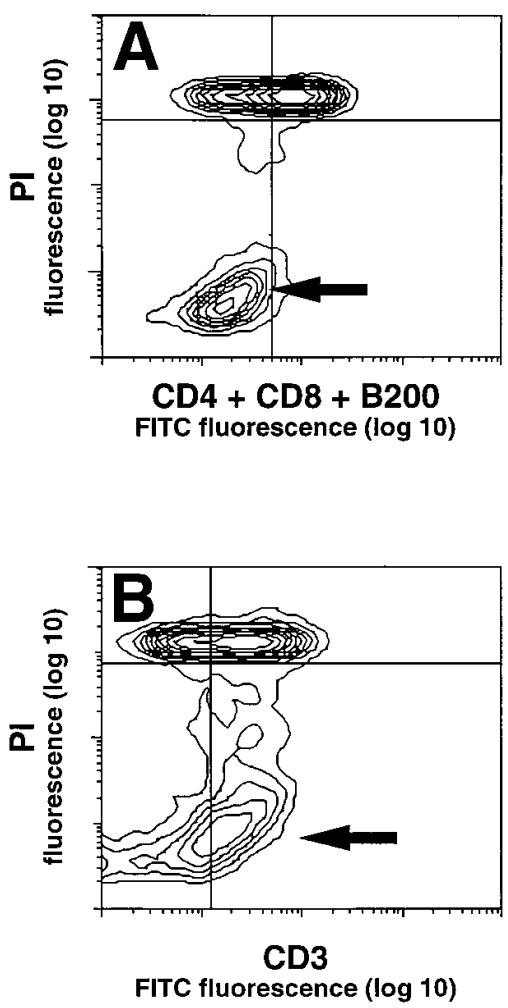

Figure 4. Representative fluorescence contour plots of BAL lymphocytes stained for DNA content and surface receptors. BAL lymphocytes obtained from normal C57BL/6J mice or SRBC-primed C57BL/6J mice $4 \mathrm{~d}$ after intratracheal $\mathrm{Ag}$ challenge were stained for surface protein expression using one or more FITC-conjugated $\mathrm{mAbs}$ as previously described (22) and then for hypodiploid DNA content by PI staining. Note absence of CD4, $\mathrm{CD} 8$, and $\mathrm{B} 220(A)$ but presence of $\mathrm{CD} 3(B)$ on apoptotic lymphocytes (arrows). Representative of five individual experiments.

shown), PI staining and flow cytometric analysis (7\% apoptosis in CsA-treated mice versus $23 \%$ apoptosis in vehicletreated mice, $P<0.05$, unpaired $t$ test), and TUNEL technique on tissue sections (not shown). Compared to mice treated with vehicle alone, mice treated with CsA had roughly twofold more BAL lymphocytes (Fig. $5 A$ ) and total leukocytes (Fig. $5 B$ ) and larger peribronchovascular mononuclear cell accumulations on day 9 (Fig. 5, $C$ and $D$ ) and day 14 after intratracheal Ag challenge. Thus, apoptosis contributes to the termination of an immune response in vivo through a CsAinhibitable mechanism.

Lung lymphocytes apoptosis requires expression of Fas and its ligand. To examine an alternative mechanism of apoptosis induction, we next studied the pulmonary immune response to $\mathrm{SRBC}$ in mice homozygous for the lpr mutation. These mice lack normal expression of CD95 (Fas) $(35,36)$, a receptor essential for certain types of lymphocyte apoptosis. Lung lymphocyte apoptosis was substantially decreased by the lpr mutation on either $\mathrm{C} 57 \mathrm{Bl} / 6$ or MRL background, as demonstrated by ethidium bromide-agarose gel electrophoresis and by analysis of DNA content by PI staining and flow cytometry (43\% apoptosis in control mice versus $9 \%$ apoptosis in lpr/lpr mice, $P<0.05$, unpaired $t$ test). Similar results were seen in two experiments with each strain background.

The decreased percentage of apoptotic BAL lymphocytes of $l p r$ homozygotes could have resulted from a failure of lymphocyte activation. To investigate this possibility, we analyzed BAL lymphocytes for expression of activation antigens CD25, CD44, CD49d, and CD69 (Table I). This analysis showed comparable expression. Although lpr homozygotes develop autoimmunity, including pulmonary fibrosis, by 6-8 mo of age (37), neither pulmonary inflammation nor fibrosis were seen in the young mice used in these experiments. Additionally, there was neither lymphadenopathy nor difference in weights or behavior between homozygotes and age-matched controls.

Lung lymphocyte apoptosis was also prevented by the gld mutation, which results in deficient expression for Fas-L, the ligand for CD95. PI staining and flow cytometry revealed $48 \%$ apoptosis in control mice versus $14 \%$ apoptosis in gld/gld mice $(P<0.05$, unpaired $t$ test); gel electrophoresis of lung lymphocyte DNA also showed absence of apoptosis in gld/gld mice (not shown). Thus, lung lymphocytes apoptosis requires normal expression of Fas and its ligand. These findings strongly suggest that the mechanism of lung lymphocyte apoptosis induction in this model system is AICD (38).

Lung inflammation to repeated antigen exposure is not down-regulated in CD95-deficient mice. Surprisingly, however, despite reduced lung lymphocyte apoptosis, inflammatory cell recruitment to a single intratracheal challenge was actually lower in the lpr mice than in $+/+$ littermates, regardless of strain background (Fig. 6). The most likely explanation is a poor response challenge by $l p r$ mutants to a single antigen challenge is a defective initial cytokine production. BL/6 lpr/ $l p r$ mice show defective cytokine production to SRBC in vitro (39) and form abnormally small lung granuloma in response to IV BCG (40). An alternative possibility is that lpr homozygotes are partially tolerized to Forssman antigen, a glycolipid oncofetal antigen which comprises a portion of the anti-SRBC response and which is expressed aberrantly by lymph nodes cells in this mutation (41).

To boost the response and to test the role of apoptosis in the clinically relevant situation of chronic antigen exposure, we performed repeated intratracheal challenges. An increasing response (measured by inflammatory cell numbers and histologically) was found after the third intratracheal antigen challenge in $l p r$ mice, in marked contrast to the waning response in normal mice (Fig. 7, $A$ and $B$ ). As with single challenge, both gel electrophoretic and flow cytometric analyses confirmed markedly decreased lung lymphocyte apoptosis in $l p r$ mice. Histologic sections confirmed the presence of increased lung inflammation in $l p r$ mice (Fig. 8, $A-D$ ).

\section{Discussion}

The results of this study indicate that apoptosis contributes to elimination of lung lymphocytes during physiologic pulmonary immune responses in mice. Three major findings support this conclusion. First, lung lymphocytes spontaneously underwent apoptosis throughout the secondary pulmonary immune response to the particulate T cell-dependent antigen SRBC. Apoptosis was demonstrated by both typical morphology and by demonstration of DNA fragmentation by three independent techniques. Second, inhibiting lung lymphocyte apoptosis by CsA treatment in vivo increased the magnitude and duration of lung lymphocyte accumulation. Third, in mutant mice whose lung lymphocytes did not undergo normal apoptosis, pulmonary inflammation increased on repeated intratracheal antigen rather than decreasing as in normal mice. These results confirm that lymphocyte apoptosis is not limited to transgenic or superantigen systems but instead occurs during physiologic responses to complex exogenous antigens. Additional important findings of this study are that apoptosis was detectable in BAL lymphocytes of normal mice; that apoptosis was restricted to cells which were negative for CD4, CD8, and B220, 

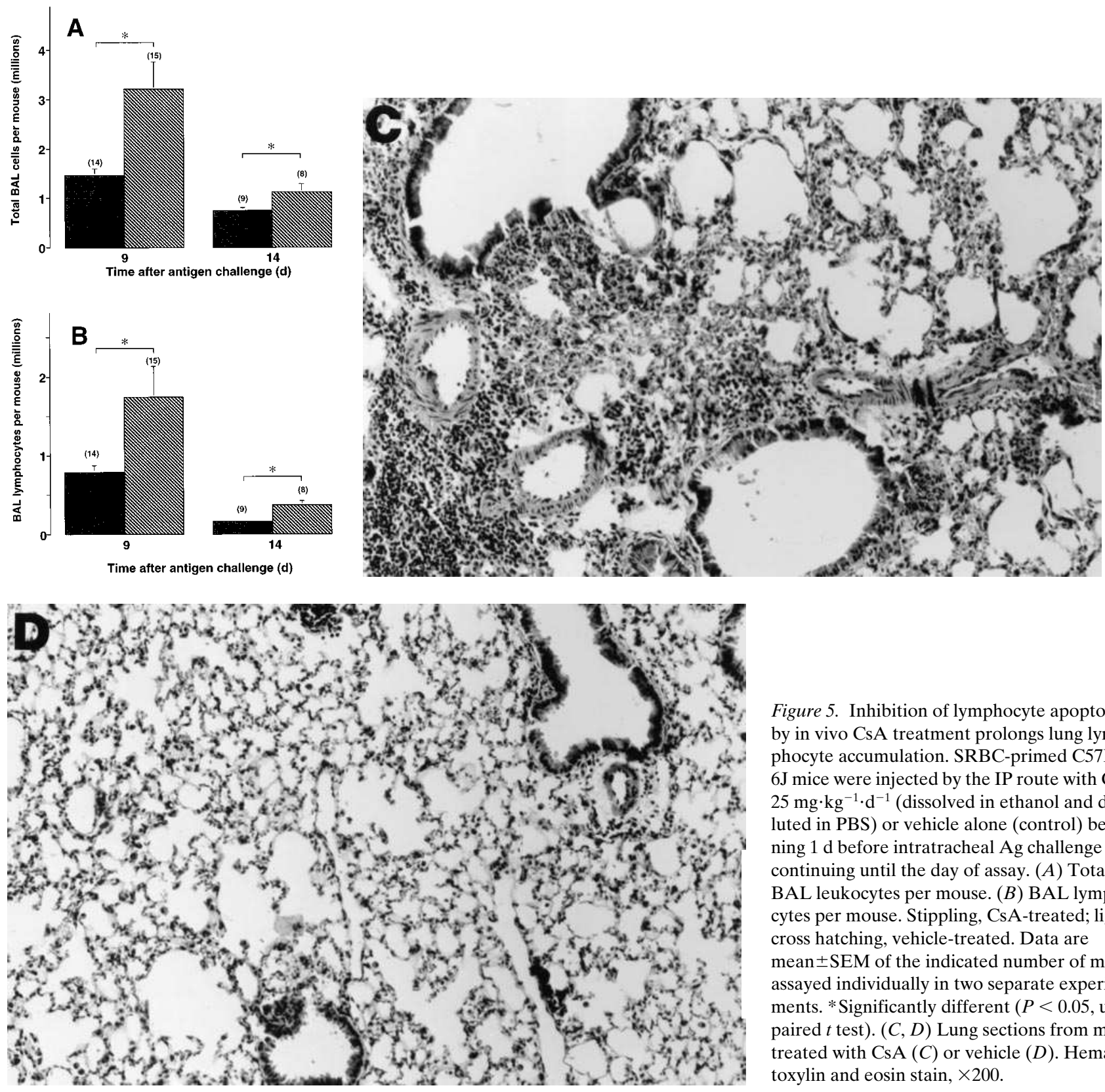

Figure 5. Inhibition of lymphocyte apoptosis by in vivo CsA treatment prolongs lung lymphocyte accumulation. SRBC-primed C57BL/ $6 \mathrm{~J}$ mice were injected by the IP route with CsA $25 \mathrm{mg} \cdot \mathrm{kg}^{-1} \cdot \mathrm{d}^{-1}$ (dissolved in ethanol and diluted in PBS) or vehicle alone (control) beginning $1 \mathrm{~d}$ before intratracheal $\mathrm{Ag}$ challenge and continuing until the day of assay. $(A)$ Total BAL leukocytes per mouse. (B) BAL lymphocytes per mouse. Stippling, CsA-treated; light cross hatching, vehicle-treated. Data are mean \pm SEM of the indicated number of mice assayed individually in two separate experiments. * Significantly different $(P<0.05$, unpaired $t$ test). (C,D) Lung sections from mice treated with CsA $(C)$ or vehicle $(D)$. Hematoxylin and eosin stain, $\times 200$.

but which were predominately $\mathrm{CD}^{+}$; and that lung lymphocyte apoptosis depended on expression of CD95 and Fas-L.

These data provide the first assessment of lymphocyte apoptosis during an in vivo pulmonary immune response. Apoptosis of lymphocytes at the site of an immune injury has been shown in a rat model of experimental allergic encephalomyelitis (14), suggesting that apoptosis contributes to immunoregulation. Our results extend that finding not only by studying the lungs, but also by demonstrating the effect of inhibiting lymphocyte apoptosis in vivo using CsA and CD95-dependence. Lymphocyte apoptosis has also been demonstrated in murine AIDS (42) and is believed to contribute to CD4 cell deficiency in HIV infection $(17,43)$.

The likely mechanism for lung lymphocyte apoptosis is AICD, which is known to be CsA-sensitive (34) and Fas-dependent (38). Alternative mechanisms are less likely. Apoptosis of lung lymphocytes could not be blocked by incubation by a variety of recombinant murine cytokines (unpublished observation) arguing against cytokine deprivation as a cause. Ablating $\mathrm{CD}^{+} \mathrm{T}$ cells in this system does not prolong lung lymphocyte accumulation (44); nor do we detect significant numbers of lung natural killer (NK) cells either phenotypically (20) or functionally (unpublished observation). Thus, granzymes, the serine proteases of cytotoxic T cells and NK cells (45) are unlikely to be important in inducing apoptosis. Induction by endogenous glucocorticoids is unlikely, as CsA enhances rather than suppresses dexamethasone-induced apoptosis of $\mathrm{T}$ cell hybridomas (46).

The finding of significant apoptosis in lung lymphocytes of normal mice suggests that apoptosis may also account for the previously noted disappearance of activated lymphocytes during passage through the lungs (2). The relative importance of 
Table I. Expression of Activation Antigens by $B A L$ Lymphocytes of CD95-deficient Mice and Normal Mice*

\begin{tabular}{lcccc}
\hline & CD25 & CD44 ${ }^{\text {high }}$ & CD49 ${ }^{\text {high }}$ & ${\mathrm{CD} 69^{+}}^{+}$ \\
\hline C57BL/6J $l p r / l p r$ & & & & \\
$\quad$ Expt 1 & 29.4 & 94.5 & 56.2 & 33.0 \\
Expt 2 & 33.0 & 96.3 & 63.5 & 37.4 \\
C57BL/6J +/+ & & & & \\
Expt 1 & 34.9 & 91.8 & 43.9 & ND $^{*}$ \\
Expt 2 & 34.7 & ND & 43.9 & 44.4 \\
& & & &
\end{tabular}

*BAL lymphocytes analyzed by flow cytometry $4 \mathrm{~d}$ after intratracheal antigen challenge. Results are expressed as percentages. ND, not determined.

this process in immune homeostasis is uncertain. Based on surface phenotype, the majority of lymphocytes isolated from the lungs of normal mice $(22,47)$ and humans $(48)$ are previously activated and thus potentially susceptible to AICD. Because lung interstitium contains a large pool of lymphocytes (49) it is possible that the lungs are a major site for physiologic lymphocyte elimination.

The results of surface phenotypic analysis are noteworthy because they confirm that the apoptotic cells we studied are predominately $\mathrm{T}$ lymphocytes. We and others $(20,22,47,50)$ have described "null" cells within light scatter-defined lymphocyte gates within BAL of mice undergoing pulmonary immune responses. However, the observation that these cells include the apoptotic fraction is novel. The finding that many lung lymphocytes are $\mathrm{CD}^{+} \mathrm{DN}$ cells without DNA fragmentation or changes in light scatter suggests that surface receptor
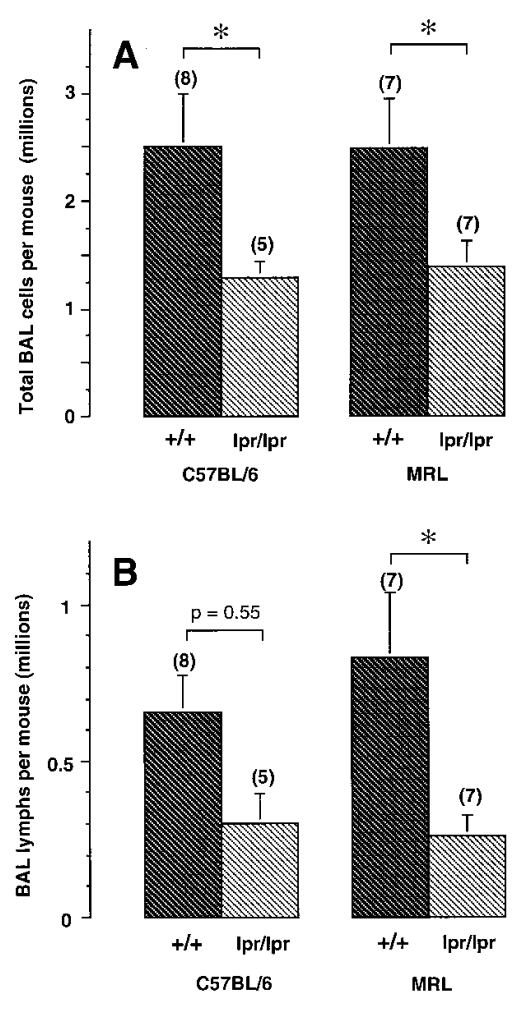

Figure 6. CD95-deficient mice have a decreased pulmonary inflammatory response to single intratracheal antigen challenge. Groups of age-matched SRBC-primed +/+ mice (dark cross hatching) or lpr/lpr mice (light cross hatching) on either a C57BL/6 or MRL background were challenged with $5 \times 10^{5}$ SRBC. Alveolar cells were collected by BAL $4 \mathrm{~d}$ after antigen challenge. $(A)$ Total BAL cells per mouse. $(B)$ BAL lymphocytes per mouse. * Significantly different $(P<0.05$, unpaired $t$ test) compared to $+/+$ mice of same strain background. Number of mice analyzed in two individual experiments indicated in parentheses.

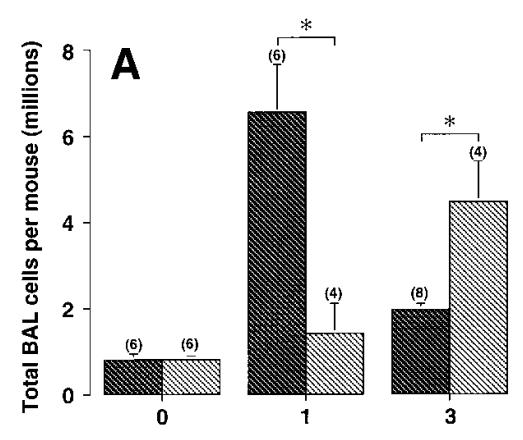

Figure 7. Repeated antigen challenge induces decreased lung lymphocyte accumulation in normal mice but not in mice deficient in CD95 expression. Groups of age matched SRBCprimed C57BL/6 +/+ mice (dark cross hatching) or lpr/lpr mice (light cross hatching) were challenged with $5 \times 10^{5}$ SRBC zero, once, or three times at weekly intervals; $\mathrm{BAL}$ cells were collected $6 \mathrm{~d}$ after the final chal-

lenge. $(A)$ Total BAL inflammatory cells per mouse. (B) BAL lymphocytes per mouse. * Significant $(P<0.05$, unpaired $t$ test) compared to $+/+$ mice. Number of mice analyzed indicated in parentheses.

down-regulation precedes commitment to apoptosis. Whether lung $\mathrm{CD}^{+} \mathrm{DN}$ which are viable at the time of isolation would also be eliminated by apoptosis is currently under study. $\mathrm{CD}^{+}$ DN cells have been isolated from peripheral blood of normal humans (51), and are increased in patients with rheumatologic diseases (52), but are quite uncommon in lymphoid organs of normal mice (33). Most $\mathrm{CD}^{+} \mathrm{DN}$ have $\gamma \delta$ TCRs $(33,51)$, but a few bear $\alpha \beta$ TCRs and, intriguingly, have both helper and cytotoxic activities in vitro, suggesting they could derive from a mixed population (53). We believe that the observed lung $\mathrm{CD}^{+} \mathrm{DN}$ cells derive from activated $\mathrm{CD}^{+}$cells (and possibly from other subsets) that have down-regulated some surface receptors. CD4 down-regulation is well-described when apoptosis is induced by anti-CD4 or gp120 protein of HIV $(16,17,54)$, but has also been described during apoptosis inducted in U937 cells without CD4 ligation (55). Absence of B220 expression distinguishes the $\mathrm{CD}^{+} \mathrm{DN}$ cells seen in our model from those which accumulate in mice with the $l p r$ or gld mutation $(33,39)$.

Despite inhibition of lymphocyte apoptosis by CsA, the pulmonary inflammatory response did wane, possibly because of lung lymphocyte emigration (56). Alternatively, it is possible that CsA simply prevented detection of apoptosis by blocking intranucleosomal DNA cleavage (detected by both the PI and TUNEL assays) but not ultimate lymphocyte destruction. Against this possibility is the observation that CsA not only blocks DNA fragmentation induced by CD3 ligation but prevents cell death (34). It is also possible that CsA simultaneously lowers lymphocyte numbers by interfering with normal mechanisms of lymphocyte retention within lung parenchyma.

Teleologically, lymphocyte elimination during waning immune responses is beneficial to limit inflammatory cytokine production and to prevent obsolete clones from consuming re- 

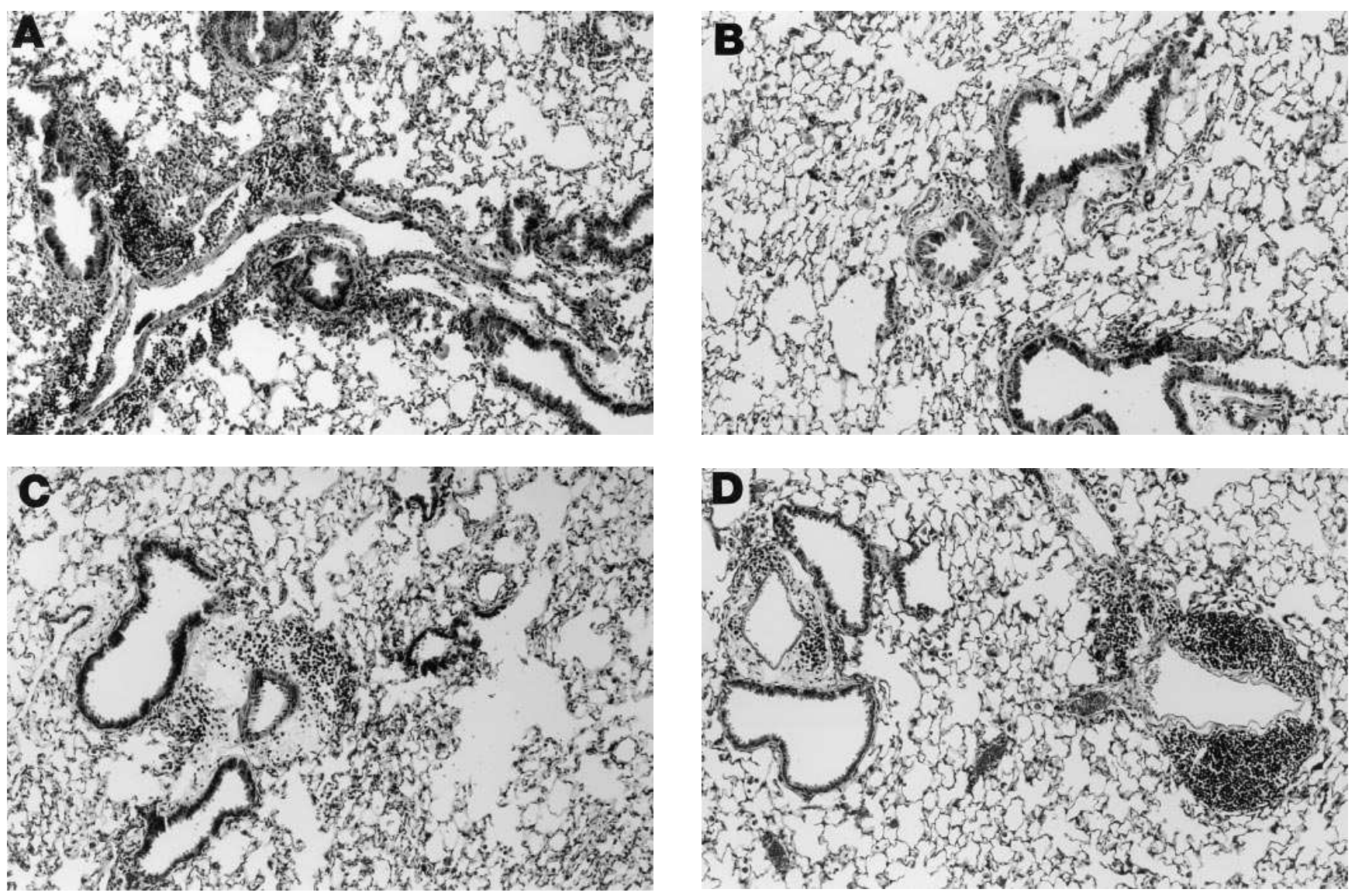

Figure 8. Repeated antigen challenge induces decreased lung inflammation in normal mice but not in mice deficient in CD95 expression. Histologic sections of lung tissue from mice described in the legend to Fig. 7. (A) C57BL/6 +/+, single intratracheal challenge; (B) C57BL/6 lpr/lpr, single intratracheal challenge; $(C) \mathrm{C} 57 \mathrm{BL} / 6+/+$, triple intratracheal challenge; $(D) \mathrm{C} 57 \mathrm{BL} / 6 \mathrm{lpr} / \mathrm{lpr}$, triple intratracheal challenge; Hematoxylin and eosin stain, $\times 200$.

sources. Apoptosis is crucial to normal immune system development, including thymocyte selection (57) and elimination of autoreactive cells, especially activated B cells, which can produce novel autoantibodies because of immunoglobulin gene hypermutation (58). Apoptosis minimizes release of toxic cellular products that would occur in necrotic cell death. In vivo, apoptotic cells are recognized efficiently by macrophages via both a thrombospondin-dependent pathway (59) and by recognition of altered membrane lipid polarity (30), and are rapidly eliminated without inducing inflammation. Because of its usual efficiency, even high levels of apoptosis may be difficult to detect in vivo (57). Our single cell assay results are a minimal estimate of the true fraction of apoptotic lung lymphocytes, because apoptotic cells ingested by macrophages were excluded. We speculate that apoptotic alveolar lymphocytes may have been detectable in this model system in part because alveolar macrophages were engorged with particulate antigen and hence less able to rapidly eliminate early apoptotic lymphocytes. It will be interesting to determine whether lymphocyte apoptosis is reduced in immunologic lung diseases characterized by lymphocyte accumulation, such as sarcoidosis and lymphocytic interstitial pneumonitis. Defining the molecular mechanisms of physiologic lymphocyte apoptosis may lead to novel insights for controlling a variety of important immunologic and infectious diseases. Herry and associates have re- cently described apoptosis of human BAL lymphocytes maintained in culture (60).

\section{Acknowledgments}

We thank Sue Stuth for preparing the TEM specimens; Jeanne M. Burger, Deborah Cieslinski, Daniel Hinshaw, Ramon Merino, Gabriel Nuñez, Geneva Oman, and Kelly Warmington for helpful suggestions; and David Humes and Robert Paine III for critiquing the manuscript. CsA was provided by Sandoz.

Supported by Research Funds from the Department of Veterans Affairs and by Specialized Center of Research in Occupational and Immunologic Lung Diseases P50 HL-46487, and RO1 HL-56309 from the US Public Health Service. Dr. Buechner-Maxwell was supported by Institutional Training Grant 5 T32 HL07749, and Dr. Kim by Individual National Science Research Award F32 HL-08763 from the USPHS.

\section{References}

1. Pabst, R., R.M. Binns, S.T. Licence, and M. Peter. 1987. Evidence of a selective major vascular marginal pool of lymphocytes in the lung. Am. Rev. Respir. Dis. 136:1213-1218.

2. Nelson, D., D. Strickland, and P.G. Holt. 1990. Selective attrition of nonrecirculating $\mathrm{T}$ cells during normal passage through the lung vascular bed. Immunology. 69:476-481. 
3. Weissler, J.C., C.R. Lyons, M.F. Lipscomb, and G.B. Toews. 1986. Human pulmonary macrophages. Functional comparison of cells obtained from whole lung and by bronchoalveolar lavage. Am. Rev. Respir. Dis. 133:473-477.

4. Ettensohn, D.B., P.A. Lalor, and N.J. Roberts, Jr. 1988. Human alveolar macrophage suppression of lymphocyte proliferation. Accessory characteristics for the generation and functional expression of con A-induced suppressor cells. Am. Rev. Respir. Dis. 137:765-773.

5. Holt, P.G. 1979. Alveolar macrophages. III. Studies on the mechanisms of inhibition of T-cell proliferation. Immunology. 37:437-445.

6. Roth, M.D., and S.H. Golub. 1993. Human pulmonary macrophages utilize prostaglandins and transforming growth factor $\beta_{1}$ to suppress lymphocyte activation. J. Leukocyte Biol. 53:366-371.

7. Harmsen, A.G., B. Muggenburg, M. Snipes, and D. Bice. 1985. The role of macrophages in particle translocation from lungs to lymph nodes. Science (Wash. DC). 230:1277-1280.

8. Thepen, T., N. Van Rooijen, and G. Kraal. 1989. Alveolar macrophage elimination in vivo is associated with an increase in pulmonary immune response in mice. J. Exp. Med. 170:499-509.

9. Sitrin, R.G., M.J. Ansfield, and H.B. Kaltreider. 1985. The effect of pulmonary surface-active material on the generation and expression of murine Band T-lymphocyte effector functions in vitro. Exp. Lung Res. 9:85-97.

10. Paine, R., III, A. Chavis, D. Gaposchkin, P. Christensen, C.H. Mody, L.A. Turka, and G.B. Toews. 1992. A factor secreted by a human pulmonary alveolar epithelial-like cell line blocks T-cell proliferation between G1 and S phase. Am. J. Respir. Cell Mol. Biol. 6:658-666.

11. Cohen, J.J., R.D. Duke, V.A. Fadok, and K.S. Sellins. 1992. Apoptosis and programmed cell death in immunity. Annu. Rev. Immunol. 10:267-293.

12. Perandones, C.E., V.A. Illera, D. Peckham, L.L. Stunz, and R.F. Ashman. 1993. Regulation of apoptosis in vitro in mature murine spleen T cells. $J$. Immunol. 151:3521-3529.

13. Wesselborg, S., U. Prüfer, M. Wild, B. Schraven, S.C. Meuer, and D. Kabelitz. 1993. Triggering via the alternative CD2 pathway induces apoptosis in activated human T lymphocytes. Eur. J. Immunol. 23:2707-2710.

14. Schmied, M., H. Breitschopf, R. Gold, H. Zischler, G. Rothe, H. Wekerle, and H. Lassmann. 1993. Apoptosis of T lymphocytes in experimental autoimmune encephalomyelitis: inflammation in the brain. Am. J. Pathol. 143: $446-452$

15. Marrack, P., P. Hugo, J. McCormack, and J.W. Kappler. 1993. Death and T cells. Immunol. Rev. 133:119-129.

16. Newell, M.K., L.J. Haughn, C.R. Maroun, and M.H. Julius. 1990. Death of mature T cells by separate ligation of CD4 and the T-cell receptor for antigen. Nature (Lond.). 347:286-289.

17. Groux, H., G. Torpier, D. Monte, Y. Mouton, A. Capron, and J.C. Ameisen. 1992. Activation-induced death by apoptosis in CD4+ T cells from human immunodeficiency virus-infected asymptomatic individuals. J. Exp. Med. 175:331-340.

18. Bice, D.E., and G.M. Shopp. 1988. Antibody responses after lung immunization. Exp. Lung Res. 14:133-156.

19. Kaltreider, H.B., J.L. Curtis, and S.M. Arraj. 1987. The mechanism of appearance of specific antibody-forming cells in lungs of inbred mice after intratracheal immunization with sheep erythrocytes. II. Dose-dependence \& kinetics. Am. Rev. Respir. Dis. 135:87-92.

20. Curtis, J.L., and H.B. Kaltreider. 1989. Characterization of bronchoalveolar lymphocytes during a specific antibody-forming cell response in the lungs of mice. Am. Rev. Respir. Dis. 139:393-400.

21. Curtis, J.L., M.L. Warnock, S.M. Arraj, and H.B. Kaltreider. 1990. Histologic analysis of an immune response in the lung parenchyma of mice: angiopathy accompanies inflammatory cell influx. Am. J. Pathol. 137:689-699.

22. Curtis, J.L., S. Kim, P.J. Scott, and V.A. Buechner-Maxwell. 1995. Adhesion receptor phenotypes of murine lung $\mathrm{CD}^{+} \mathrm{T}$ cells during a pulmonary immune response to sheep erythrocytes. Am. J. Respir. Cell Mol. Biol. 12:520530 .

23. Kaltreider, H.B., J.L. Caldwell, and P.K. Byrd. 1986. The capacity of normal murine alveolar macrophages to function as antigen-presenting cells for the initiation of primary antibody-forming cell responses to sheep erythrocytes in vitro. Am. Rev. Respir. Dis. 133:1097-1104.

24. McLeod, E., J. Caldwell, and H.B. Kaltreider. 1978. Pulmonary immune responses of inbred mice: appearance of antibody-forming cells in C57BL/6 mice after intrapulmonary or systemic immunization with sheep erythrocytes. Am. Rev. Respir. Dis. 118:561-571.

25. Urdahl, K.B., D.M. Pardoll, and M.K. Jenkins. 1994. Cyclosporin A inhibits positive selection and delays negative selection in $\alpha \beta$ transgenic mice. $J$. Immunol. 152:2853-2859.

26. Nicoletti, I., G. Migliorati, M. Pagliacci, F. Grignani, and C. Riccardi. 1991. A rapid and simple method for measuring thymocyte apoptosis by propidium iodine staining and flow cytometry. J. Immunol. Method. 139:271-279.

27. Julius, M.H., E. Simpson, and L. A. Herzenberg. 1973. A rapid method for the isolation of functional thymus-derived murine lymphocytes. Eur. J. Immunol. 3:645-649.

28. Gavrieli, Y., Y. Sherman, and S.A. Ben-Sasson. 1992. Identification of programmed cell death in situ via specific labeling of nuclear DNA fragmentation. J. Cell Biol. 119:493-501.
29. Noguchi, P. 1991. Use of flow cytometry for DNA analysis. In Current Protocols in Immunology. J. Coligan, A. Kruisbeek, D. Margulies, E. Shevach, and W. Strober, editors. John Wiley \& Sons, Inc., New York. 5.7.1-5.7.6.

30. Fadok, V.A., D.R. Voelker, P.A. Campbell, J.J. Cohen, D.L. Braton, and P.M. Henson. 1992. Exposure of phophatidylserine on the surface of apoptotic lymphocytes triggers specific recognition and removal by macrophages. $J$. Immunol. 148:2207-2216.

31. Vermes, I., C. Haanen, H. Steffens-Nakken, and C. Reutelingsperger 1995. A novel assay for apoptosis. Flow cytometric detection of phosphatidylserine expression on early apoptotic cells using fluorescein labeled Annexin V. J. Immunol. Methods. 184:39-51.

32. Zar, J.H. 1974. Biostatistical Analysis. Prentice-Hall, Englewood Cliffs, NJ. $718 \mathrm{pp}$

33. Reimann, J. 1991. Double-negative (CD4-CD8-), TCR $\alpha \beta$-expressing, peripheral T cells. Scand. J. Immunol. 34:679-688.

34. Shi, Y., B.M. Sahai, and D.R. Green. 1989. Cyclosporin A inhibits activation-induced cell death in T-cell hybridomas and thymocytes. Nature (Lond.). 339:625-626.

35. Watanabe-Fukunaga, R., C.I. Brannan, N.G. Copeland, N.A. Jenkins, and S. Nagata. 1992. Lymphoproliferation disorder in mice explained by defects in Fas antigen that mediates apoptosis. Nature (Lond.). 356:314-317.

36. Chu, J.L., J. Drappa, A. Parnassa, and K.B. Elkon. 1993. The defect in Fas mRNA expression in MRL/lpr mice is associated with insertion of the retrotransposon, ETn. J. Exp. Med. 178:723-730.

37. Sunderrajan, E.V., W.N. McKenzie, T.R. Lieske, J.L. Kavanaugh, S.R. Braun, and S.E. Walker. 1986. Pulmonary inflammation in autoimmune MRL Mp-lpr/lpr mice. Histopathology and bronchoalveolar lavage evaluation. Am. J. Pathol. 124:353-362.

38. Dhein, J., H. Walczk, C. Bäumier, K.-M. Debain, and P.H. Krammer. 1995. Autocrine T-cell suicide mediated by APO-1/(Fas/CD95). Nature (Lond.). 373:438-441.

39. Cohen, P.L., and R.A. Eisenberg. 1991. Lpr and gld: single gene models of systemic autoimmunity and lymphoproliferative disease. Annu. Rev. Immunol. 9:243-269.

40. Okuyama, H., K. Yamamoto, T. Matsunaga, S. Kobayashi, and A. Tashiro. 1986. Analysis of defective delayed-type hypersensitivity in autoimmune mice bearing lpr gene. Clin. Exp. Immunol. 63:87-94.

41. Katagiri, T., T. Mori, T. Nakano, K. Ueno, and K. Kano. 1984. Aberrant expression of Forssman and Paul-Bunnell antigens on lymph node cells of MRL/MP-lpr/lpr mice. J. Immunol. 133:3143-3148.

42. Cohen, D.A., E.A. Fitzpatrick, S.S. Barve, J.M. Guthridge, R.J. Jacob, L. Simmerman, and A.M. Kaplan. 1993. Activation-dependent apoptosis in

CD4+ T cells during murine AIDS. Cell. Immunol. 151:392-403.

43. Terai, C., R.S. Kornbluth, C.D. Pauza, D.D. Richman, and D.A. Carson. 1991. Apoptosis as a mechanism of cell death in cultured T lymphoblasts acutely infected with HIV-1. J. Clin. Invest. 87:1710-1715.

44. Curtis, J.L., P.K. Byrd, M.L. Warnock, J.M. Beck, and H.B. Kaltreider. 1993. Pulmonary lymphocyte recruitment: depletion of CD8+ T cells does not impair the pulmonary immune response to intratracheal antigen. Am. J. Respir. Cell Mol. Biol. 9:90-98.

45. Berke, G. 1994. The binding and lysis of target cells by cytotoxic lymphocytes: molecular and cellular aspects. Annu. Rev. Immunol. 12:735-773.

46. Zacharchuk, C.M., M. Mercep, P.K. Chakraborti, S.S. Simons, Jr., and J.D. Ashwell. 1990. Programmed T lymphocyte death. Cell activation- and steroid-induced pathways are mutually antagonistic. J. Immunol. 145:4037-4045.

47. Kennedy, J.D., C.A. Hatfield, S.F. Fidler, G.E. Winterrowd, J.V. Haas, J.E. Cin, and I.M. Richards. 1995. Phenotypic characterization of T lymphocyte emigrating into lung tissue and the airway lumen after antigen inhalation in sensitized mice. Am. J. Respir. Cell Mol. Biol. 12:613-623.

48. Marathias, K.P., F.I. Preffer, C. Pinto, and R.L. Kradin. 1991. Most human pulmonary infiltrating lymphocytes display the surface immune phenotype and functional responses of sensitized T cells. Am. J. Respir. Cell Mol. Biol. 5: $470-476$.

49. Holt, P.G., A. Degerbrodt, T. Venaille, C. O’Leary, K. Krska, J. Flexman, H. Farrell, G.R. Shellam, P. Young, J. Penhale, T. Robertson, and J.M. Papadimitriou. 1985. Preparation of interstitial lung cells by enzymatic digestion of tissue slices: preliminary characterization by morphology and performance in functional assays. Immunology. 54:139-147.

50. Chang, J.C.C., L. Zhang, S.G. Distler, G. Ziang, and A.M. Kaplan. 1992. Characterization and function of CD3+ CD $4-\mathrm{CD} 8-\mathrm{TcR}-\alpha \beta$ bearing cells infiltrating the lung during the immune response. Reg. Immunol. 4:25-33.

51. Bender, A., and D. Kabelitz. 1990. CD4-CD8- human T cells: phenotypic heterogeneity and activation requirements of freshly isolated "doublenegative" T cells. Cell. Immunol. 128:542-554.

52. Shivakumar, S., G. Tsokos, and S. Datta. 1989. T cell receptor $\alpha \beta$ expressing double negative (CD4-/CD8-) and CD4+ T helper T cells in humans augment the production of pathogenic anti-DNA autoantibodies associated with lupus nephritis. J. Immunol. 143:103-112.

53. Matsumoto, M., M. Yasukawa, A. Inatsuki, and Y. Kobayashi. 1991. Human double-negative (CD4-CD8-) T cells bearing $\alpha \beta \mathrm{T}$ cell receptor possess both helper and cytotoxic activities. Clin. Exp. Immunol. 85:525-530.

54. Wang, Z., A. Dudhane, T. Orlikowsky, K. Clarke, X. Li, Z. Darzyn- 
kiewicz, and M.K. Hoffmann. 1994. CD4 engagement induces Fas antigendependent apoptosis of T cells in vivo. Eur. J. Immunol. 24:1549-1552.

55. Malorni, W., R. Rivabene, M.T. Santini, S. Paradisi, F. Iosi, and G. Donelli. 1993. Down-modulation of CD4 antigen during programmed cell death in U937 cells. FEBS Lett. 336:335-339.

56. Pabst, R., and R.M. Binns. 1995. Lymphocytes migrate from the bronchoalveolar space to regional bronchial lymph nodes. Am. J. Respir. Crit. Care Med. 151:495-499.

57. Surh, C.D., and J. Sprent. 1994. T-cell apoptosis detected in situ during positive and negative selection in the thymus. Nature (Lond.). 372:100-103.
58. Diamond, B., and M.D. Scharff. 1984. Somatic mutation of the T15 heavy chain gives rise to an antibody with autoantibody specificity. Proc. Natl. Acad. Sci. USA. 81:5841-5844.

59. Savill, J., I. Dransfield, N. Hogg, and C. Haslett. 1990. Vitronectin receptor-mediated phagocytosis of cells undergoing apoptosis. Nature (Lond.). 343:170-173.

60. Herry, I., M. Bonay, F. Bouchonnet, M.P. Schuller, D. Lecossier, A. Tazi, D.H. Lynch, A.J. Hance. 1996. Extensive apoptosis of lung T-lymphocytes maintained in vitro. Am. J. Respir. Cell Mol. Biol. 15:339-347. 